\title{
Modeling the Thermal Conductivity of Pure and Mixed Heavy $n$-Alkanes Suitable for the Design of Phase Change Materials
}

\author{
F. Paradela, ${ }^{1}$ A. J. Queimada, ${ }^{1}$ I. M. Marrucho, ${ }^{1}$ C. P. Neto, ${ }^{1}$ \\ and J. A. P. Coutinho ${ }^{1,2}$
}

Received January 11, 2005

\begin{abstract}
Recent interest in the use of paraffin waxes is related to energy management provided by phase change materials (PCMs) where a tunable melting temperature range is used to store or release latent heat by means of the solid-liquid phase change. Thermal conductivity is an essential property for the correct design of these new materials, with applications as different as household heating and insulation, clothes for athletes and campers, or solar energy storage. As the interest in most of these heavier $n$-alkanes was small until recently, the available data are particularly limited. The purpose of this work was to develop a simple and accurate model to estimate the liquid thermal conductivity of heavy $n$-alkanes suitable for the design of efficient PCMs. Corresponding states theory was selected, based on previous improvements for equilibrium and transport properties of pure and mixed heavy $n$-alkanes, using a second-order perturbation model on the Pitzer acentric factor. Results for the $n$-alkane series show that this new model is able to predict thermal conductivities in a broad temperature and pressure range with a deviation of $3 \%$, whereas common deviations using a linear perturbation model are close to $16 \%$. Results for one ternary and five binary mixtures indicate that the extension to mixtures is straightforward with the best results obtained using a mixing rule previously proposed for viscosity.
\end{abstract}

KEY WORDS: corresponding states; energy storage; model; $n$-alkanes; paraffinic wax; phase change materials; thermal conductivity.

\footnotetext{
${ }^{1}$ CICECO, Chemistry Department, Aveiro University, 3810-193 Aveiro, Portugal.

${ }^{2}$ To whom correspondence should be addressed. E-mail: jcoutinho@dq.ua.pt
} 


\section{INTRODUCTION}

Efficient heat recovery systems are necessary, as frequently heat production and utilization periods are different. Water is still used as a storage medium, although this sensible heat storage route provides lower storage densities $\left(\mathrm{J} \cdot \mathrm{m}^{-3}\right)$ than latent heat storage methods. For example, as mentioned by Farid et al. [1], to store $1 \mathrm{MJ}, 16000 \mathrm{~kg}$ of water may be required instead of $5300 \mathrm{~kg}$ required for latent heat storage based on an organic phase change material (PCM).

Phase change materials are organic or inorganic materials able to store or release thermal energy under controlled circumstances. Typically these materials should have a large melting latent heat, high thermal conductivity, a melting temperature in the desired working range, melt congruently with no subcooling, be low in cost, chemically stable, non-toxic and non-corrosive.

Most organic PCM's are non-corrosive and chemically stable, exhibit little or no subcooling and have low-vapor pressure and high-latent heat. Their disadvantages are low-thermal conductivity, high changes in volume on phase change, and flammability. Inorganic compounds have higher latent heat and thermal conductivity, are non-flammable and low in cost, but they are corrosive and suffer from decomposition and subcooling, which can affect their phase change characteristics.

Commercial paraffin waxes, containing several heavy $n$-alkanes, are cheap and have a moderate thermal energy storage density $\left(\sim 200 \mathrm{~kJ} \cdot \mathrm{kg}^{-1}\right.$ or $150 \mathrm{MJ} \cdot \mathrm{m}^{-3}$ ) [1] and a wide range of melting temperatures. They are chemically inert and stable, with no phase segregation or subcooling. However, they have low thermal conductivity $\left(\sim 0.2 \mathrm{~W} \cdot \mathrm{m}^{-1} \cdot \mathrm{K}^{-1}\right)$, thus requiring larger heat transfer surfaces which are usually achieved by encapsulation. Some common applications of paraffin wax as a PCM are solar energy storage, temperature controlled clothing for athletes and campers, and household heating and insulation.

The selection of a PCM should first be based on its melting temperature. Density is another important property, as it affects the storage per unit volume, while thermal conductivity determines heat transfer rates.

For the correct design of new PCMs, it is important to know the thermal conductivity at the desired temperature working range. Since experimental data for heavy $n$-alkanes are scarce and measurements are time consuming and often difficult to perform, the alternative to the design engineer is to select models from which thermal conductivity (and other important properties) can be obtained within the required accuracy. With this regard, corresponding states models offers several advantages such as 
simplicity, a solid theoretical background, versatility, and low usage of input experimental data.

In previous works [2-5], a model was derived based on the corresponding states theory and used to estimate thermophysical properties as different as liquid density, vapor pressure, vapor-liquid interfacial tension, and viscosity of pure and mixed $n$-alkanes. In the present work, this model will be evaluated for the prediction of the thermal conductivity of $n$-alkanes as a function of temperature, pressure, and composition.

\section{CORRESPONDING STATES PRINCIPLE}

Following its initial empirical formulation by van der Waals, the corresponding states principle has evolved in order to deal with non-spherical and polar molecules. Its success is grounded in the accuracy obtained over broad temperature and pressure conditions and its strong theoretical basis [6-11], while being mathematically simple and using a minimum amount of experimental information. One of its advantages is that the same formalism can be used for different properties, whereas the only changes are the definition of the reduced property and the equation used for the reference system, or the reference system itself. Since these models do not use any experimental data of the estimated property of the target fluid, they are also predictive. The only experimental information required from the target fluid are the critical properties and the Pitzer acentric factor.

The application of corresponding states models extends from equilibrium properties such as vapor pressure [12-16], liquid density [14, 16-18], or surface tension $[4,5,14,19,20]$ to transport properties such as viscosity $[2,14,21-24]$ and thermal conductivity $[14,25-27]$.

In its original form, the reduced compressibility factor $\left(Z_{\mathrm{r}}\right)$ was expressed in terms of a universal function of two parameters, the dimensionless temperature $\left(T_{\mathrm{r}}\right)$ and molar volume $\left(V_{\mathrm{r}}\right)$ (or pressure, $p_{\mathrm{r}}$ ):

$$
\begin{aligned}
& Z_{\mathrm{r} j}\left(T_{\mathrm{r}}, V_{\mathrm{r}}\right)=Z_{\mathrm{r} 0}\left(T_{\mathrm{r}}, V_{\mathrm{r}}\right) \\
& T_{\mathrm{r}}=\frac{T}{T_{\mathrm{c}}}, \quad V_{\mathrm{r}}=\frac{V}{V_{\mathrm{c}}}, \quad p_{\mathrm{r}}=\frac{p}{p_{\mathrm{c}}}
\end{aligned}
$$

where $Z$ is the compressibility factor, $p V /(\mathrm{R} T)$, and the subscripts $\mathrm{r}$ and $\mathrm{c}$ stand for reduced and critical property, and $j$ and 0 for target and spherical reference fluid, respectively.

Experimental evidence has, however, shown that this two-parameter corresponding states approach was limited to the noble gases and nearly spherical molecules, such as nitrogen, oxygen, and methane. To extend this theory to a broader range of fluids, additional characterization parameters 
have been introduced to account for the non-conformalities. One of the approaches performs a multi-parameter Taylor series expansion of the property of interest about the new parameters. An additional third parameter, the Pitzer acentric factor, $\omega$, was initially introduced [13] to generalize the scope of the corresponding states principle including fluids whose force fields slightly depart from those of the original spherical symmetry. Reduced pressure was used instead of reduced volume due to the uncertainty usually ascribed to the measurement of critical volumes. A Taylor series expansion of the property of interest is performed about this third parameter, with the series being usually truncated beyond the first derivative:

$$
Z_{\mathrm{r} j}\left(T_{\mathrm{r}}, p_{\mathrm{r}}, \omega\right)=Z_{\mathrm{r} 0}\left(T_{\mathrm{r}}, p_{\mathrm{r}}\right)+\omega Z_{\mathrm{r}}\left(T_{\mathrm{r}}, p_{\mathrm{r}}\right)
$$

where $Z_{\mathrm{r} 0}$ has the same meaning as in Eq. (1) and $Z_{\mathrm{r}}$ is a function that represents the departure from the spherical symmetry, the derivative $\partial z / \partial w$. In spite of the analytic formalism of Eq. (3), values for the functions $Z_{\mathrm{r} 0}$ and $Z_{\mathrm{r}}$ were only presented in tabular form by Pitzer and coworkers.

With the advent of cheaper and faster computers, Lee et al. [28] suggested replacing the derivative in the Taylor series with its finite difference:

$$
Z_{\mathrm{r} j}\left(T_{\mathrm{r}}, p_{\mathrm{r}}, \omega\right)=Z_{\mathrm{r} 0}\left(T_{\mathrm{r}}, p_{\mathrm{r}}\right)+\frac{\omega_{j}}{\omega_{1}}\left[Z_{\mathrm{r} 1}\left(T_{\mathrm{r}}, p_{\mathrm{r}}\right)-Z_{\mathrm{r} 1}\left(T_{\mathrm{r}}, p_{\mathrm{r}}\right)\right]
$$

with subscript 1 representing a non-spherical reference fluid $(\omega>0)$.

Although this new formalism contained a correction for the departure from spherical symmetry, some problems arose in the description of polar or asymmetric systems. Since Eq. (4) still contains a spherical reference fluid, $(\omega=0)$, large interpolations/extrapolations were frequent in the description of real fluids. Another problem was related with the widespread use of methane as the spherical reference fluid. Since methane has a triple point relatively high compared with the majority of the hydrocarbons, some low temperature calculations would result in the extrapolation of the methane equation of state introducing considerable errors in the predicted data.

Following Teja and coworkers [16, 18-20, 24, 29, 30], the spherical reference in Eq. (4) was abandoned. Therefore, both reference fluids could be similar to the evaluating fluid, reducing the errors due to large interpolations/extrapolations. Several thermophysical properties were estimated according to this new framework with very good predictive results:

$$
X_{\mathrm{r}}=X_{\mathrm{r}_{1}}+\frac{\omega-\omega_{1}}{\omega_{2}-\omega_{1}}\left(X_{\mathrm{r}_{2}}-X_{\mathrm{r}_{1}}\right)
$$


where $X_{\mathrm{r}}$ stands for the reduced property to be evaluated and subscripts 1 and 2 for the two reference fluid properties at the same reduced conditions as those of the target fluid. In all cases, good agreement with experimental data was obtained in the range of fluids covered by the two references. However, considerable deviations can be found if the reference fluids are far apart in the series from the target fluid, either interpolating or extrapolating [2, 5]. In an attempt to correct for these deviations, and based on the dependence of the desired properties with $\omega$ (or chain length), the Taylor series expansion of the reduced property was carried out to the second-order term:

$$
\begin{aligned}
& X_{\mathrm{r}}=X_{\mathrm{r}_{1}}+D_{1}\left(\omega-\omega_{1}\right)+D_{2}\left(\omega-\omega_{1}\right)\left(\omega-\omega_{2}\right) \\
& D_{1}=\frac{X_{\mathrm{r}_{2}}-X_{\mathrm{r}_{1}}}{\omega_{2}-\omega_{1}}, \quad D_{2}=\frac{\frac{X_{\mathrm{r}_{3}}-X_{\mathrm{r}_{1}}}{\omega_{3}-\omega_{1}}-\frac{X_{\mathrm{r}_{2}}-X_{\mathrm{r}_{1}}}{\omega_{2}-\omega_{1}}}{\omega_{3}-\omega_{2}}
\end{aligned}
$$

A third reference fluid is introduced, with the advantage that no change in the reference system has to be done while studying a large range of fluids or an asymmetric mixture. If instead, the Teja approach (Eq. (5)) is adopted for asymmetric mixtures with a single reference system, considerable deviations resulting from large interpolations/extrapolations may be found as was already shown for surface tension, liquid density, and viscosity $[2,5]$ and will be shown below for thermal conductivity.

\section{RESULTS AND DISCUSSION}

The linear perturbation, Eq. (5), and the second-order perturbation models, Eq. (6), presented in Section 2, were evaluated for the estimation of the thermal conductivity of pure and mixed $n$-alkanes from methane up to $n$-tetracosane, as a function of temperature, pressure, and composition. The aim was to select a corresponding states model able to predict the thermal conductivity of pure and mixed heavier $n$-alkanes, without requiring any experimental information from the system under study. Since for heavier $n$-alkanes the available experimental data is reduced, this will help the engineer to better design new PCMs based on commercial paraffin waxes.

Thermal conductivity was reduced according to the following equation, already used in previous thermal conductivity estimations based on corresponding states theory [14]:

$$
\lambda_{\mathrm{r}}=\frac{\lambda V_{\mathrm{c}}^{2 / 3} \mathrm{MW}}{T_{\mathrm{c}}^{1 / 2}}
$$


where $\lambda$ stands for thermal conductivity $\left(\mathrm{W} \cdot \mathrm{m}^{-1} \cdot \mathrm{K}^{-1}\right), V_{\mathrm{c}}$ is the critical volume $\left(\mathrm{cm}^{3} \cdot \mathrm{mol}^{-1}\right)$, MW is the molar mass $\left(\mathrm{g} \cdot \mathrm{mol}^{-1}\right)$, and $T_{\mathrm{c}}$ is the critical temperature $(\mathrm{K})$.

Another reducing equation, a function of the critical pressure and critical temperature, was proposed before [25-27], but our previous results showed that the reduction presented in Eq. (8) proved adequate, while maintaining the original formalism of the corresponding states principle.

Pure and mixed $n$-alkane experimental thermal conductivities at different temperatures and pressures were collected from different sources [3152], and afterwards the pure component data was correlated as a function of temperature and pressure [40], (if considerable experimental data were available) for each $n$-alkane:

$$
\begin{aligned}
& \lambda(T, p)=\frac{-\lambda_{\text {atm }}(T)}{A \ln \left\{\frac{B(T)+p}{B(T)+p_{\text {atm }}}\right\}-1} \\
& B(T)=B_{1}+B_{2} T+B_{3} T^{2} \\
& \lambda_{\text {atm }}(T)=C_{1}+C_{2} T+C_{3} T^{2}
\end{aligned}
$$

where $T$ is the absolute temperature $(\mathrm{K}), p$ is the system pressure (bar $\left.\left(10^{5} \mathrm{~Pa}\right)\right), A, B_{1}-B_{3}$, and $C_{1}-C_{3}$ are correlation parameters presented in Table I for the selected reference fluids, and subscript atm stands for atmospheric pressure.

\subsection{Pure Components at Atmospheric Pressure}

In order to compare the performance of the linear and the new second-order perturbation models for the $n$-alkane series, a collection of reduced temperatures covering a broad range of the liquid region was selected for evaluation, starting at $T_{\mathrm{r}}=0.45$, close to the triple point of methane, and ending at $T_{\mathrm{r}}=0.75$. The higher limit for the

Table I. Correlating Coefficients of the Reference Fluids to be Used with Eq. (9)

\begin{tabular}{cccccccc}
\hline$n$-Alkane & $A$ & $B_{1}$ & $B_{2}$ & $B_{3} \times 10^{3}$ & $C_{1}$ & $C_{2} \times 10^{3}$ & $C_{3} \times 10^{7}$ \\
\hline $\mathrm{CH}_{4}$ & 0.2854 & 893.8 & -5.706 & 9.360 & 0.4278 & -2.579 & 39.51 \\
$n-\mathrm{C}_{4} \mathrm{H}_{10}$ & 0.1641 & 840.4 & -3.077 & 2.863 & 0.2344 & -0.3450 & -3.187 \\
$n-\mathrm{C}_{6} \mathrm{H}_{14}$ & 0.1648 & 1290 & -4.604 & 4.150 & 0.2322 & -0.4073 & 0.9157 \\
$n-\mathrm{C}_{10} \mathrm{H}_{22}$ & 0.2094 & 3823 & -15.79 & 18.01 & 0.2349 & -0.4222 & 2.544 \\
$n-\mathrm{C}_{16} \mathrm{H}_{34}$ & & & & & 0.2742 & -0.5763 & 4.691 \\
$n-\mathrm{C}_{24} \mathrm{H}_{50}$ & & & & & 0.2470 & -0.3410 & 1.856 \\
\hline
\end{tabular}


reduced temperature was established to avoid the extrapolation to higher temperatures of the thermal conductivity correlating equations. No pressure effect was considered at this point, as for the heavier $n$-alkanes, no pressure dependent data are available.

Experimental critical properties were used when available [53]. For those $n$-alkanes whose experimental data were unavailable, correlations were used. The critical temperature was obtained from a Tsonopoulos correlation [54], the critical pressure from Magoulas and Tassios [55], the critical volume from Marano and Holder [56], and the Pitzer acentric factor from Han and Peng [57]. Arguments for selecting these correlations were presented elsewhere [58].

A search for the best reference systems was performed for both the linear (Eq. (5)), and the second-order perturbation (Eq. (6)), models. These reference systems are presented in Table II.

Figure 1, showing the reduced thermal conductivity as a function of the acentric factor at a reduced temperature of 0.52 , clearly provides evidence that a linear perturbation (Eq. (5)) cannot describe the behavior of the heavier $n$-alkanes. The introduction of a second-order term (Eq. (6)), is required for an adequate description of the properties of heavy $n$-alkanes.

Results are presented in Table III as a function of reduced temperature only. No pressure effects were considered at this point. Table III shows how the introduction of the second-order term of the Taylor series expansion improves the prediction of the reduced thermal conductivity at all the studied reduced temperatures. The average deviation is reduced 10 times with this new model.

Figures 2 and 3 illustrate the percent average deviation of the estimated reduced property (thermal conductivity) as a function of the chain length of the $n$-alkane. It can be seen that the linear approach proposed by Teja and co-workers has some limitations for methane, ethane, and the heavier $n$-alkanes, and that the average deviation decreases considerably around the reference fluids, confirming that this model is not able to predict the trend in the reduced property, as shown before in Fig. 1, due to the nonlinearity of the reduced thermal conductivity as a function of the Pitzer acentric factor, $\omega$.

Table II. Selected Reference Systems

\begin{tabular}{lll}
\hline Model & Linear Perturbation & Second-Order Perturbation \\
\hline Reference System & $n-\mathrm{C}_{4} \mathrm{H}_{10} / n-\mathrm{C}_{16} \mathrm{H}_{34}$ & $\mathrm{CH}_{4} / n-\mathrm{C}_{4} \mathrm{H}_{10} / n-\mathrm{C}_{24} \mathrm{H}_{50}$ \\
\hline
\end{tabular}




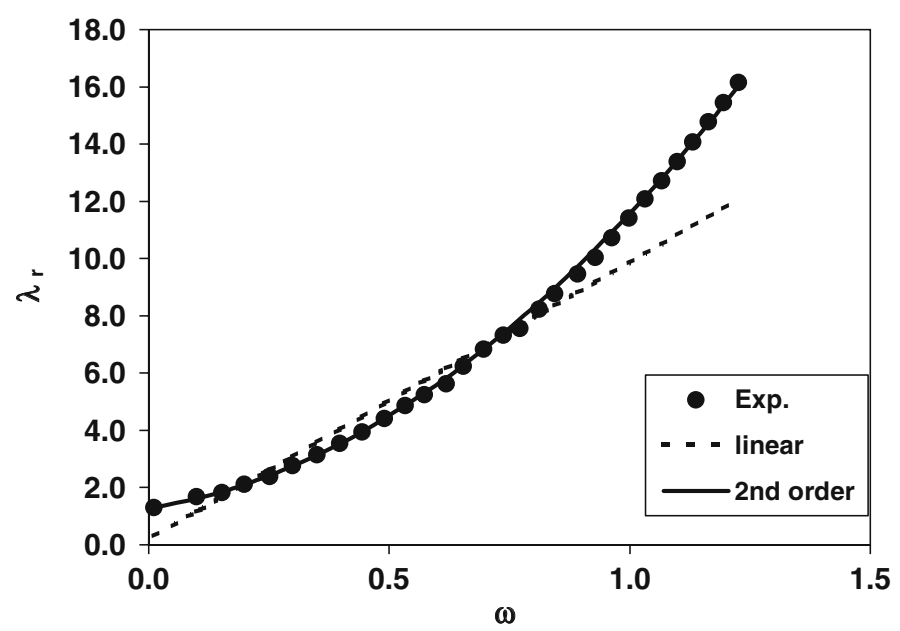

Fig. 1. Reduced thermal conductivity as a function of the acentric factor $(\omega)$ at $T_{\mathrm{r}}=0.52$.

Table III. Average Absolute Deviation (AAD) of the Linear and Second-order Models as a Function of Reduced Temperature

\begin{tabular}{lcc}
\hline & \multicolumn{2}{c}{ AAD (\%) } \\
\cline { 2 - 3 }$T_{\mathrm{r}}$ & Linear & Second order \\
\hline 0.45 & 15.4 & 1.31 \\
0.48 & 15.4 & 1.33 \\
0.52 & 15.4 & 1.40 \\
0.55 & 15.4 & 1.49 \\
0.58 & 15.4 & 1.60 \\
0.62 & 15.3 & 1.74 \\
0.65 & 15.3 & 1.85 \\
0.68 & 15.3 & 1.96 \\
0.72 & 15.2 & 2.11 \\
0.75 & 15.1 & 2.29 \\
Average & 15.32 & 1.71 \\
\hline
\end{tabular}

Pure component thermal conductivity estimations using the proposed reference systems are presented in Table IV. As can be seen, for the second-order corresponding states model, an average absolute deviation below 3\% results, while using the linear approach and one single reference system, $16 \%$ deviation is obtained. 


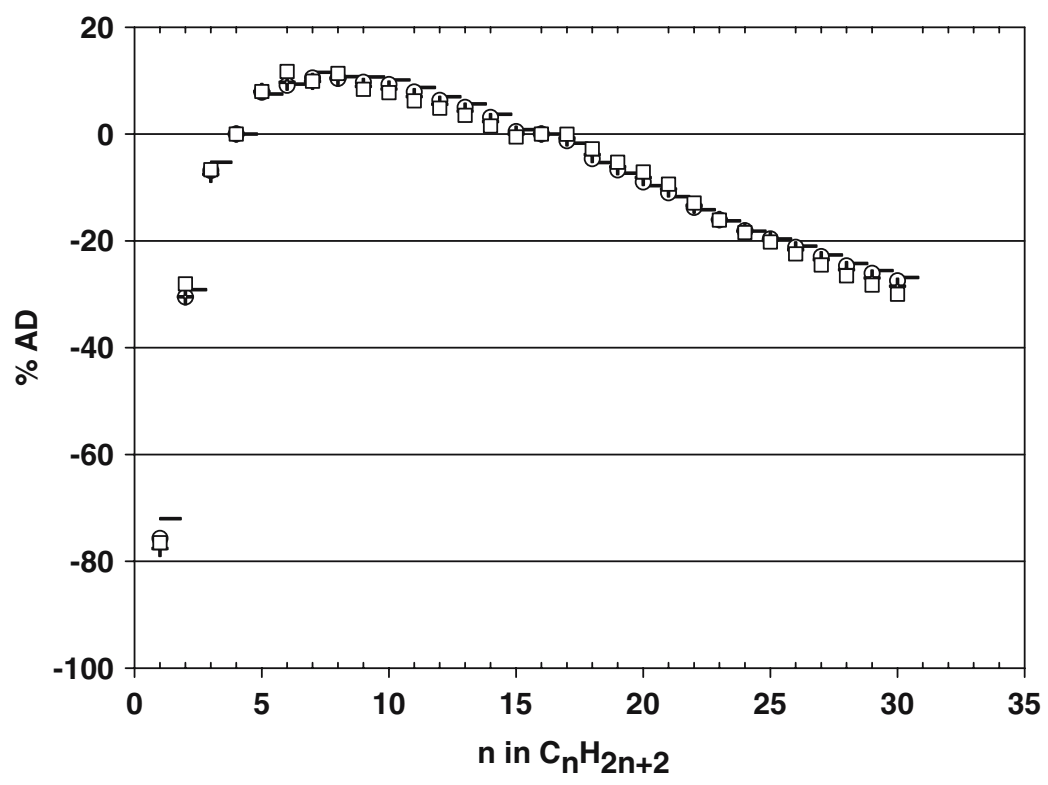

Fig. 2. Average deviation of the thermal conductivity predicted with the linear perturbation model as a function of the chain length of the $n$-alkane. - : $T_{\mathrm{r}}=0.45 ; \bigcirc$ : $T_{\mathrm{r}}=0.55 ; \times: T_{\mathrm{r}}=0.65 ; \square: T_{\mathrm{r}}=0.75$.

\subsection{Pure Components at High Pressure}

For modeling high-pressure thermal conductivities, we need to select three reference fluids for which pressure dependent data are available. The first step is to correlate the parameters $A$ and $B$ in Eq. (9) for these fluids. Given the evaluating fluid target temperature and pressure, we calculate at the same reduced conditions (Eq. (2)) the reference fluid thermal conductivities and incorporate them in the model equation (Eq. (6)).

More than one thousand $n$-alkane pressure dependent thermal conductivities from methane up to $n$-tetradecane were collected from different data sources. For the purposes of this evaluation, methane, $n$-hexane, and $n$-decane were selected as reference fluids, given their broad temperature and pressure ranges (Table V) and the lack of high-pressure data for heavier $n$-alkanes.

As can be seen in Table $\mathrm{V}$, broad temperature and pressure ranges are involved, and this frequently requires extrapolation of the reference fluid correlating equations. This explains the increase in deviation with respect to those presented before in Table IV, where only temperaturedependent data were considered. Still, the average deviation is below $4 \%$. 


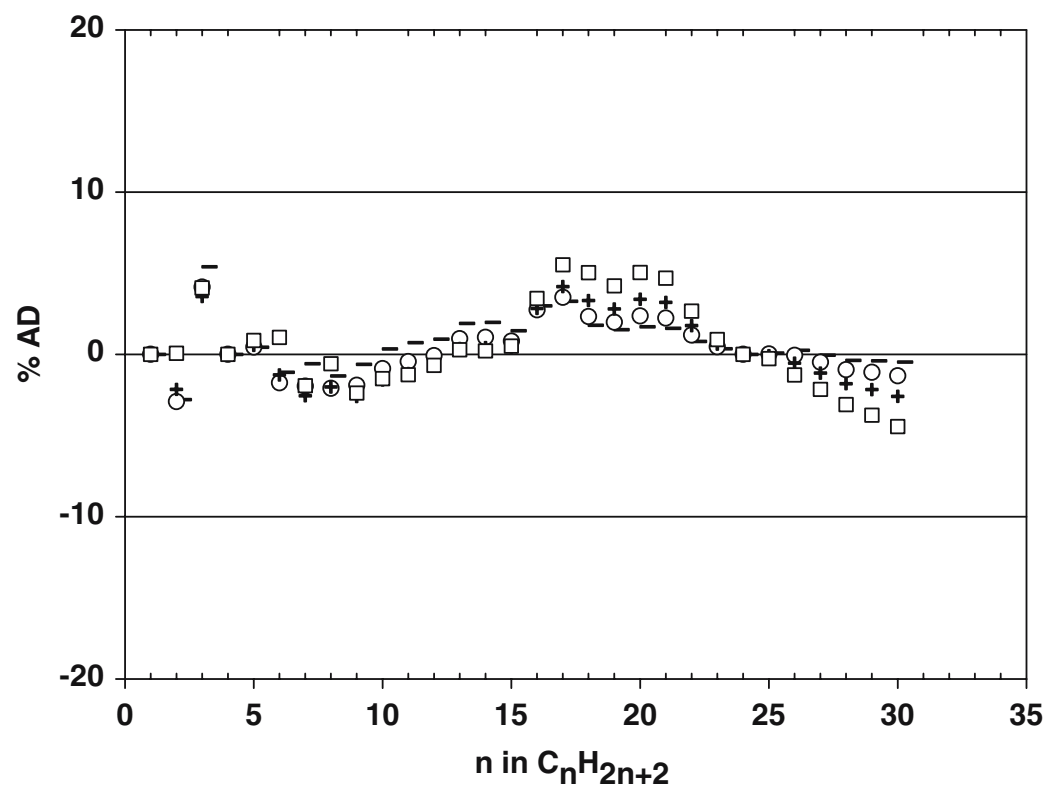

Fig. 3. Average deviation of the thermal conductivity predicted with the second-order perturbation model as a function of the chain length of the $n$-alkane. $-: T_{\mathrm{r}}=0.45$; $\bigcirc: T_{\mathrm{r}}=0.55 ; \times: T_{\mathrm{r}}=0.65 ; \square: T_{\mathrm{r}}=0.75$.

Higher deviation is obtained for $n$-butane, but this can be explained by the low thermal conductivities of some of the selected measurements (below $0.1 \mathrm{~W} \cdot \mathrm{m}^{-1} \cdot \mathrm{K}^{-1}$ ), which, again, require extrapolation of the reference fluid correlating equations, thus enlarging the deviation with respect to the experimental data. For thermal conductivities above $0.1 \mathrm{~W} \cdot \mathrm{m}^{-1} \cdot \mathrm{K}^{-1}$, the average absolute deviation reduces to $3 \%$.

\subsection{Mixtures}

The extension to mixtures uses the following mixing and combining rules for the pure component properties:

$$
\begin{aligned}
& \omega_{m x}=\sum_{i} x_{i} \omega_{i} \\
& V_{\mathrm{c} m x}=\sum_{i} \sum_{j} x_{i} x_{j} V_{\mathrm{c} i j} \\
& T_{\mathrm{c} m x} V_{\mathrm{c} m x}=\sum_{i} \sum_{j} x_{i} x_{j} T_{\mathrm{c} i j} V_{\mathrm{c} i j}
\end{aligned}
$$


Table IV. Pure $n$-Alkane Corresponding States Results

\begin{tabular}{|c|c|c|c|c|}
\hline \multirow[b]{2}{*}{$n$-Alkane } & \multicolumn{2}{|c|}{ AAD $(\%)$} & \multirow[b]{2}{*}{$T$ range $(\mathrm{K})$} & \multirow[b]{2}{*}{ No. of data point } \\
\hline & $\begin{array}{c}\text { Linear } \\
\text { perturbation }\end{array}$ & $\begin{array}{c}\text { Second-order } \\
\text { perturbation }\end{array}$ & & \\
\hline $\mathrm{CH}_{4}$ & 127 & 2.0 & $95-190$ & 26 \\
\hline $\mathrm{C}_{2} \mathrm{H}_{6}$ & 42 & 4.5 & $188.71-255.37$ & 7 \\
\hline $\mathrm{C}_{3} \mathrm{H}_{8}$ & 11 & 1.4 & $93.15-277.59$ & 12 \\
\hline$n-\mathrm{C}_{4} \mathrm{H}_{10}$ & 0.30 & 0.3 & $143.15-273.15$ & 11 \\
\hline$n-\mathrm{C}_{5} \mathrm{H}_{12}$ & 8.6 & 2.3 & $146.27-410.93$ & 26 \\
\hline$n-\mathrm{C}_{6} \mathrm{H}_{14}$ & 11 & 1.5 & $183.15-366.48$ & 23 \\
\hline$n-\mathrm{C}_{7} \mathrm{H}_{16}$ & 13 & 1.8 & $183.15-373.15$ & 47 \\
\hline$n-\mathrm{C}_{8} \mathrm{H}_{18}$ & 13 & 1.2 & $223.15-373.15$ & 31 \\
\hline$n-\mathrm{C}_{9} \mathrm{H}_{20}$ & 13 & 0.4 & $223.15-373.15$ & 30 \\
\hline$n-\mathrm{C}_{10} \mathrm{H}_{22}$ & 12 & 2.9 & $243.15-415.97$ & 44 \\
\hline$n-\mathrm{C}_{11} \mathrm{H}_{24}$ & 6.4 & 5.0 & $293.15-448.15$ & 13 \\
\hline$n-\mathrm{C}_{12} \mathrm{H}_{26}$ & 8.8 & 1.8 & $263.15-483.57$ & 26 \\
\hline$n-\mathrm{C}_{13} \mathrm{H}_{28}$ & 6.1 & 2.5 & $273.15-613.15$ & 38 \\
\hline$n-\mathrm{C}_{14} \mathrm{H}_{30}$ & 6.0 & 2.5 & $284.25-509.8$ & 44 \\
\hline$n-\mathrm{C}_{15} \mathrm{H}_{32}$ & 4.7 & 4.1 & $283.15-473.15$ & 35 \\
\hline$n-\mathrm{C}_{16} \mathrm{H}_{34}$ & 2.8 & 3.6 & $295.75-533.15$ & 37 \\
\hline$n-\mathrm{C}_{17} \mathrm{H}_{36}$ & 5.1 & 4.0 & $309.37-573.15$ & 51 \\
\hline$n-\mathrm{C}_{18} \mathrm{H}_{38}$ & 7.7 & 4.4 & $308.15-573.15$ & 57 \\
\hline$n-\mathrm{C}_{19} \mathrm{H}_{40}$ & 11 & 5.2 & $313.15-593.15$ & 52 \\
\hline$n-\mathrm{C}_{20} \mathrm{H}_{42}$ & 11 & 3.4 & $310.15-613.15$ & 25 \\
\hline$n-\mathrm{C}_{21} \mathrm{H}_{44}$ & 10 & 2.4 & $313.15-703.15$ & 16 \\
\hline$n-\mathrm{C}_{22} \mathrm{H}_{46}$ & 14 & 2.2 & $333.15-473.15$ & 14 \\
\hline$n-\mathrm{C}_{23} \mathrm{H}_{48}$ & 15 & 1.3 & $323.15-623.15$ & 14 \\
\hline$n-\mathrm{C}_{24} \mathrm{H}_{50}$ & 19 & 2.4 & $335.45-473.15$ & 20 \\
\hline Average & 16 & 2.6 & Total & 699 \\
\hline
\end{tabular}

$$
\begin{aligned}
& V_{\mathrm{c} i j}=\frac{1}{8}\left(V_{\mathrm{c} i}^{\frac{1}{3}}+V_{\mathrm{c} j}^{\frac{1}{3}}\right)^{3} \\
& T_{\mathrm{c} i j}=\sqrt{T_{\mathrm{c} i} T_{\mathrm{c} j}}\left(\frac{\sqrt{V_{\mathrm{c} i} V_{\mathrm{c} j}}}{V_{\mathrm{c} i j}}\right)^{(n / 3)-1}
\end{aligned}
$$

where indexes $i$ and $j$ in the above equations represent pure components. The mixing rule for the cross-critical temperature (Eq. (14)) where the exponent $n$ can be used as a fitting parameter, replacing binary interaction parameters, was proposed by Coutinho et al. [59] and was previously applied to model surface tensions and viscosities of asymmetric $n$-alkane mixtures [3, 4]. This equation reduces to common combining rules if, for example, we set $n=3$ or $n=6$. 
Table V. Pressure Dependent Results from the Second-Order Corresponding States Model

\begin{tabular}{cllrrl}
\hline & & \multicolumn{5}{c}{ No. } \\
$n$-Alkane & $T$ range (K) & $p$ range (bar) & AAD $(\%)$ & of points & \multicolumn{1}{c}{ References } \\
\hline $\mathrm{CH}_{4}$ & $100-277.15$ & $1-700.83$ & 5.8 & 133 & {$[32,47,50,52]$} \\
$\mathrm{C}_{2} \mathrm{H}_{6}$ & $100-310$ & $1 \times 10^{-6}-700$ & 2.5 & 79 & {$[33]$} \\
$\mathrm{C}_{3} \mathrm{H}_{8}$ & $192.93-268.59$ & $5.76-709.9$ & 3.2 & 101 & {$[42]$} \\
$n-\mathrm{C}_{4} \mathrm{H}_{10}$ & $296.6-518$ & $10-701$ & 9.3 & 34 & {$[34]$} \\
$n-\mathrm{C}_{5} \mathrm{H}_{12}$ & $223.15-373.15$ & $0.01-3329$ & 2.7 & 135 & {$[35,43,46,47,49]$} \\
$n-\mathrm{C}_{6} \mathrm{H}_{14}$ & $248.15-373.15$ & $1-2500$ & 1.9 & 90 & {$[35,36,37,40,46]$} \\
$n-\mathrm{C}_{7} \mathrm{H}_{16}$ & $248.15-443.8$ & $1-2500.3$ & 2.0 & 116 & {$[35-38,40,46-48,51]$} \\
$n-\mathrm{C}_{8} \mathrm{H}_{18}$ & $248.15-633.15$ & $0.01-2000.5$ & 4.1 & 253 & {$[35,37,39,40,46-48]$} \\
$n-\mathrm{C}_{9} \mathrm{H}_{20}$ & $248.15-373.15$ & $0.002-1$ & 1.6 & 62 & {$[35,39,46-48]$} \\
$n-\mathrm{C}_{10} \mathrm{H}_{22}$ & $248.15-373.15$ & $1-2000.5$ & 1.2 & 104 & {$[35-37,40,41,46-48]$} \\
$n-\mathrm{C}_{11} \mathrm{H}_{24}$ & $284.61-373.36$ & $2 \times 10^{-4}-1500$ & 3.1 & 59 & {$[32,39,45,47]$} \\
$n-\mathrm{C}_{12} \mathrm{H}_{26}$ & $273.15-373.15$ & $1-2000.5$ & 3.6 & 57 & {$[37,40,47]$} \\
$n-\mathrm{C}_{13} \mathrm{H}_{28}$ & $298.15-373.15$ & $1-1672$ & 5.4 & 40 & {$[44,47]$} \\
$n-\mathrm{C}_{14} \mathrm{H}_{30}$ & $284.25-373.15$ & $2 \times 10^{-5}-1$ & 2.4 & 30 & {$[39,45,47]$} \\
& & & Average & 3.5 & Total $=1293$ \\
& &
\end{tabular}

Different mixing rules, such as the mole fraction average, proposed by Kay [60], or those used by Mollerup and Rowlinson [61], Prausnitz and Gunn [62], Plocker et al. [29], and Teja and Rice [24] were evaluated. Since the available mixture data do not contain heavier components, the correlation of the $n$ parameter in Eq. (14) was not performed, and instead, the value previously found for viscosity $(n=-1.5)$ was selected. As explained before [3], although typical $n$-values are in the range 3-7.5, the modeling of transport properties using corresponding states theory with the onefluid concept presents several simplifications, particularly for asymmetric mixtures, as discussed by Ely and Hanley [21]. Therefore, this optimized

Table VI. Mixture Modeling Results with the Second-Order Corresponding States Model

\begin{tabular}{lcc}
\hline Mixture & AAD (\%) & Source \\
\hline$n-\mathrm{C}_{6} \mathrm{H}_{14}+n-\mathrm{C}_{8} \mathrm{H}_{18}$ & 5.3 & {$[63]$} \\
$n-\mathrm{C}_{7} \mathrm{H}_{16}+n-\mathrm{C}_{10} \mathrm{H}_{22}$ & 5.0 & {$[48]$} \\
$n-\mathrm{C}_{11} \mathrm{H}_{24}+n-\mathrm{C}_{7} \mathrm{H}_{16}$ & 0.5 & {$[45]$} \\
$n-\mathrm{C}_{16} \mathrm{H}_{34}+n-\mathrm{C}_{7} \mathrm{H}_{16}$ & 1.0 & {$[45]$} \\
$n-\mathrm{C}_{16} \mathrm{H}_{34}+n-\mathrm{C}_{11} \mathrm{H}_{24}$ & 0.5 & {$[45]$} \\
$n-\mathrm{C}_{7} \mathrm{H}_{16}+n-\mathrm{C}_{11} \mathrm{H}_{24}+n-\mathrm{C}_{16} \mathrm{H}_{34}$ & 0.4 & {$[45]$} \\
Average & 1.8 & \\
\hline
\end{tabular}


value accounts for these simplifications, and should thus be considered as a fitting parameter. Curiously, this viscosity-optimized parameter gives the lowest deviation if compared with results from other mixing rules. Mixture results obtained in this way are reported in Table VI. A global average absolute deviation below $2 \%$ was obtained using the reference system suggested in Section 3.1, as the collected data are only temperature dependent. Unfortunately, no heavy $n$-alkane data are available in order to evaluate the model for these systems.

\section{CONCLUSION}

The extension of a previously established second-order corresponding states model for liquid thermal conductivities was presented and discussed. It was first shown that the introduction of the second-order term of the Taylor series expansion of the reduced thermal conductivity in the Pitzer acentric factor is required for adequate modeling of the entire $n$-alkane series. Using this model, one single reference system is adequate for the correct modeling of any pure or mixed $n$-alkanes. Thermal conductivities of $24 n$-alkanes were predicted in broad temperature ranges with a global average deviation below $3 \%$, whereas common deviations using the linear perturbation model with a single reference system was found to be more than five times larger. Pressure dependent data were also modeled, although this time the $n$-alkane range was smaller due to the lack of highpressure experimental results for the heavier $n$-alkanes. The average deviation was still below $4 \%$, considering the broader temperature and pressure ranges. The application of this model to mixtures is straightforward given the pure component critical properties and Pitzer acentric factors. Using a generalized mixing rule, it was found that an average deviation below $2 \%$ was obtained for five binary and one ternary $n$-alkane systems. Unfortunately, no mixture results containing $n$-alkane heavier components were found in the literature search that was performed for this work. Still, the results obtained for the pure components suggest that this model should be an adequate tool for the estimation of the liquid thermal conductivities of mixtures containing heavier $n$-alkanes, such as those that have been proposed for the production of PCMs.

\section{ACKNOWLEDGMENTS}

Financial support from INTERREG IIIB, FEDER and Fundação para a Ciência e a Tecnologia (Project POCTI/CTM/60288/2004) is gratefully acknowledged. A. J. Queimada thanks Fundação para a Ciência e a Tecnologia for his post-doctoral scholarship BPD/12871/2003. Yolanda 
Lobato and Nuria Balaguer are acknowledged for performing some initial calculations.

\section{REFERENCES}

1. M. M. Farid, A. M. Khudhair, S. A. K. Razack, and S. Al-Hallaj, Energy Convers. Manage. 45:1597 (2004).

2. A. J. Queimada, E. H. Stenby, I. M. Marrucho, and J. A. P. Coutinho, Fluid Phase Equilib. 212:303 (2003).

3. A. J. Queimada, I. M. Marrucho J. A. P. Coutinho, and E. H. Stenby, Int. J. Thermophys. 26:47 (2005).

4. A. J. Queimada, F. A. E. Silva, A. I. Caço, I. M. Marrucho, and J. A. P. Coutinho, Fluid Phase Equilib. 214:211 (2003).

5. A. J. Queimada, I. M. Marrucho, and J. A. P. Coutinho, Fluid Phase Equilib. 183-184:229 (2001).

6. J. F. Ely and I. M. Marrucho, in Equations of State for Fluids and Fluid Mixtures, Part 1, J. V. Sengers, R. F. Kayser, C. J. Peters, and H. J. White Jr., eds. (Elsevier, Amsterdam, 2000).

7. E. Guggenheim, J. Chem. Phys. 13:253 (1945).

8. T. W. Leland and P. S. Chappelear, Ind. Eng. Chem. 60:15 (1968).

9. T. M. Reed and K. E. Gubbins, Applied Statistical Mechanics (McGraw-Hill, New York, 1973), Chap. 11.

10. J. S. Rowlinson and F. L. Swinton, Liquids and Liquid Mixtures (Butterworths, London, 1982).

11. K. S. Pitzer, J. Chem. Phys. 7:583 (1939).

12. D. L. Morgan and R. Kobayashi, Fluid Phase Equilib. 94:51 (1994).

13. K. S. Pitzer, D. Z. Lippmann, R. F. Curl, C. M. Huggins, and D. E. Petersen, J. Am. Chem. Soc. 77:3433 (1955).

14. B. E. Poling, J. M. Prausnitz, and J. P. O'Connell, The Properties of Gases and Liquids, 5th Ed. (McGraw-Hill, New York, 2000).

15. H. W. Xiang, Chem. Eng. Sci. 57:1439 (2002).

16. A. S. Teja, S. I. Sandler, and N. C. Patel, Chem. Eng. J. 21:21 (1981).

17. F. Munõz and R. Reich, Fluid Phase Equilib. 13:171 (1983).

18. A. S. Teja, AIChE J. 26:337 (1980).

19. P. Rice and A. S. Teja, J. Coll. Interf. Sci. 86:158 (1982).

20. Y. Zuo and E. H. Stenby, Can. J. Chem. Eng. 75:1130 (1997).

21. J. F. Ely and H. J. M. Hanley, Ind. Eng. Chem. Fund. 20:323 (1981).

22. S. A. Klein, M. O. McLinden, and A. Laesecke, Int. J. Refrig. 20:208 (1997).

23. M. Lee and M. Wei, J. Chem. Eng. Jpn. 26:159 (1993).

24. A. S. Teja and P. Rice, Chem. Eng. Sci. 36:7 (1981).

25. M Arikol and H. Gürbüz, Can. J. Chem. Eng. 70:1157 (1992).

26. K. S. Pedersen and A. Fredenslund, Chem. Eng. Sci. 42:182 (1987).

27. A. S. Teja and G. Tardieu, Can. J. Chem. Eng. 66:980 (1988).

28. B. Lee and M. Kesler, AIChE J. 21:510 (1975).

29. U. Plocker, H. Knapp, and J. Prausnitz, Ind. Eng. Chem. Proc. Des. Dev. 17:324 (1978).

30. D. S. H. Wong, S. I. Sandler, and A. S. Teja, Fluid Phase Equilib. 14:79 (1983).

31. DIPPR, Thermophysical Properties Database (1998).

32. U. B. Magomedov, High Temp. 41:32 (2003). 
33. V. Vesovic, W. A. Wakeham, J. Leuttmer-Strathmann, J. V. Sengers, J. Millat, E. Vogel, and M. J. Assael, Int. J. Thermophys. 15:33 (1994).

34. C. A. Nieto de Castro, R. Tufeu, and B. Le Neindre, Int. J. Thermophys. 4:11 (1983).

35. H. Watanabe and D. J. Seong, Int. J. Thermophys. 23:337 (2002).

36. M. J. Assael, E. Charitidou, C. A. Nieto de Castro, and W. A. Wakeham, Int. J. Thermophys. 8:663 (1987).

37. H. Kashiwagi, M. Oshi, Y. Tanaka, H. Kubota, and T. Makita, Int. J. Thermophys. 3:101 (1982).

38. P. G. Knibbe and J. D. Raal, Int. J. Thermophys. 8:181 (1987).

39. J. C. G. Calado, J. M. N. Fareleira, C. A. Nieto de Castro, and W. A. Wakeham, Int. J. Thermophys 4:193 (1983).

40. Y. Tanaka, Y. Itani, H. Kubota, and T. Makita, Int. J. Thermophys. 9:331 (1988).

41. M. J. Assael, E. Charitidou, and L. Karagiannidis, Int. J. Thermophys. 12:491 (1991).

42. R. C. Prasad, G.Wang, and J. E. S. Venart, Int. J. Thermophys. 10:1013 (1989).

43. A. M. F. Palavra, W. A. Wakeham, and M. Zalaf, Int. J. Thermophys. 8:305 (1987).

44. M. Mustafa, M. Sage, and W. A. Wakeham, Int. J. Thermophys. 3:217 (1982).

45. Y. Wada, Y. Nagasaka, and A. Nagashima, Int. J. Thermophys. 6:251 (1985).

46. J. A. Dean, Lange's Handbook of Chemistry, 14th Ed. (McGraw Hill, New York, 1992).

47. D. R. Lide, ed., CRC Handbook of Chemistry and Physics, 81st Ed. (CRC Press, New York, 2000).

48. K. Ogiwara, Y. Aral, and S. Saito, Ind. Eng. Chem. Fund. 19:295 (1980).

49. R. B. Perry and D. W. Green, eds., Perry's Chemical Engineers Handbook, 7th Ed. (McGraw Hill, New York, 1997).

50. R. C. Prasad, N. Mani, and J. E. S. Venart, Int. J. Thermophys. 5:265 (1984).

51. L. Qun-Fang, L. Rui-Sen, N. Dan-Yan, L. Qun-Fang, L. Rui-Sen, N. Dan-Yan, and H. Yu-Chun, J. Chem. Eng. Data 42:971 (1997).

52. H. M. Roder, Int. J. Thermophys. 6:119 (1985).

53. D. Ambrose and C. Tsonopoulos, J. Chem. Eng. Data 40:531 (1995).

54. C. Tsonopoulos, AIChE. J. 33: 2080 (1987).

55. K. Magoulas and D. Tassios, Fuid Phase Equilib. 56:119 (1990).

56. J. Marano and G. Holder, Ind. Eng. Chem. Res. 36:1895 (1997).

57. B. Han and D. Peng, Can. J. Chem. Eng. 71:332 (1993).

58. A. J. Queimada, Properties and Low Temperature Behavior of Hydrocarbon Mixtures. (Ph. D. thesis, Aveiro University, Aveiro, Portugal, 2004), Chap. II.

59. J. A. P. Coutinho, P. M. Vlamos, and G. M. Kontogeorgis, Ind. Eng. Chem. Res. 39:3076 (2000).

60. W. B. Kay, Ind. Eng. Chem. 28:1014 (1938).

61. J. Mollerup and J. S. Rowlinson, Chem Eng. Sci. 29:1373 (1974).

62. J. M. Prausnitz and R. Gunn; AIChE J. 494:430 (1958).

63. Bruce E. Gammon, ed., Transport Properties and Related Thermodynamic Data of Binary Mixtures (American Institute of Chemical Engineers, New York, 1993). 